\title{
INCIDENCE OF TRAVELERS' DIARRHEA AMONG JAPANESE VISITING THAILAND
}

\author{
YOSHINORI MITSUI ${ }^{1}$, CHARNCHUDHI CHANYASANHA², CHAWEEWON BOONSHUYAR ${ }^{3}$, \\ MASAAKI SHIMADA ${ }^{1}$, KAZUHIKO MOJI ${ }^{1}$ \\ Accepted 2, February, 2004
}

\begin{abstract}
A cross-sectional survey of 327 Japanese short-term travelers ( $\leq 3$ weeks) arriving in Bangkok, Thailand was conducted to assess the incidence of travelers' diarrhea (TD) as well as their symptoms and treatment-seeking behaviors. The incidence of the first episode of TD (FTD) was ascertained retrospectively by questionnaire. Reported by 69 travelers, FTD clustered within the first 8 days of arrival in Thailand, and the incidence rate varied from $2 \%$ to $8 \%$ with the highest incidence on the third day.

Cumulative probability of FTD was 19\% for those arriving in Thai directly from Japan, $42 \%$ for those arriving via Southeast Asia, and 25\% for those arriving via other regions at Day 7 by the Kaplan-Meier survival analysis. Log rank test revealed a higher FTD risk for travelers arriving via other Southeast Asian countries than for those arriving directly from Japan $(P<0.005)$. Of all the 69 FTD episodes, $33 \%$ had classic TD defined as $\geq 3$ unformed stools per 24 hours with at least one accompanying symptom, $49 \%$ had moderate TD defined as $\leq 2$ unformed stools with at least one additional symptom or more unformed stools without additional symptoms, and $17 \%$ had mild TD defined as with $\leq 2$ unformed stools without additional symptoms. Cumulative probability of FTD at Day 7 was $12 \%$ for classic TD, 25\% for classic plus moderate TD and 30\% for all the TD. More than $38 \%$ of travelers with diarrhea took medicine brought from Japan. Among travelers with classic TD, 35\% bought medicine in Thailand, whereas $47-50 \%$ of travelers with moderate and mild TD took only rest without any treatment.
\end{abstract}

Key words: incidence, diarrhea, travelers, Japanese, Thailand,.

\section{INTRODUCTION}

Travelers' diarrhea (TD) is a common health problem among travelers. Annually, over 50 million people from industrialized countries visit developing countries. Ten to 80 percent of travelers suffer from diarrhea (Black, 1990; Cobelens et al., 1998; Steffen, 1986; von Sonnenburg et al., 2000). Although TD is a self-limiting illness that usually resolves spontaneously within a few days, travelers often have to change their itinerary because of it (Hill, 2000; Steffen et al., 1999).

Annually, 3 million Japanese people travel to Southeast Asia (Statistics on Legal Migrants, Ministry of Justice in Japan, 2001). Enteropathogens causing diarrhea were isolated from a high proportion (65.3\%) of Japanese travelers who arrived from Southeast Asia and had suffered from TD (Ueda et al., 1996). There is a risk of spread of imported causative agents in homeland countries (Wittlinger $e t$ al., 1995). Nevertheless, the TD of Japanese travelers has never been studied in Southeast Asia before, although TD was studied among United States troops and US Peace Corps volunteers in Thailand (Beecham et al., 1997; Echeverria et al., 1981; Taylor et al., 1985). Epidemiological data on Japanese TD in Southeast Asia will lead to valuable advice for Japanese travelers regarding prevention and treatment.

We therefore studied the incidence of TD as well as their symptoms and treatment-seeking behaviors for TD by a cross-sectional survey in Japanese travelers on adventurestyle trips (hereafter, backpackers) arriving in Bangkok, Thailand. Here we report on the results in Thailand, a country visited by one million Japanese annually (Statistics on Legal Migrants, Ministry of Justice in Japan, 2001).

\footnotetext{
1 Research Center for Tropical Infectious Diseases, Institute of Tropical Medicine, Nagasaki University, Nagasaki, 852-8523, Japan

2 Department of Microbiology, Faculty of Public Health, Mahidol University, 420/1 Rajvithi Rd., Rajthevee, Bangkok 10400, Thailand.

${ }^{3}$ Department of Biostatistics, Faculty of Public Health, Mahidol University, 420/1 Rajvithi Rd., Rajthevee, Bangkok 10400, Thailand. Correspondence to Dr. Yoshinori Mitsui

Research Center for Tropical Infectious Diseases, Institute of Tropical Medicine,

Nagasaki University, 1-12-4 Sakamoto, Nagasaki, 852-8523 Japan.

Tel: +81-95-849-7869 Fax: +81-95-849-7869 e-mail: yoshi856@yahoo.co.jp
} 


\section{MATERIALS AND METHODS}

This study was conducted between January and February 2002 in the Khaosan Road area, Bangkok, Thailand. The subjects were Japanese travelers who were more than 15 years old and stayed in Thailand for 3 weeks or less. Three hundred and eighty four Japanese travelers participated in this study with informed consent. The study was conducted by a self-administered questionnaire. Of the 384 subjects, 57 (15\%) who had stayed more than 3 weeks in Thailand before the interview were excluded to reduce recall bias. Thus, 327 Japanese travelers were used for the analysis.

As in previous studies (Steffen et al., 1999; von Sonnenburg et al., 2000), classic TD was defined as the passage of three or more unformed stools per 24 hours with as least one accompanying symptom such as nausea or vomiting, abdominal pain, fever, or blood in stools. Moderate TD was defined as either the passage of one to two unformed stools with at least one additional symptom, or more unformed stools without additional symptoms. Mild TD was defined as the passage of one to two unformed stools without additional symptoms.

Daily incidence rates (IRs) of having the first TD episode (FTD) on Day N were calculated by the following formula:

$\begin{aligned} \operatorname{IR}(n)= & \frac{100 \times \text { Number of travelers who had FTD on Day N }}{\text { Number of travelers who stayed on Day N and who }} \\ & \text { had never had FTD until Day N-1 }\end{aligned}$

The IRs of FTD were presented as simple proportions with $95 \%$ confidence interval $(95 \% \mathrm{Cl})$. Data management was performed with Microsoft Excel (Version 8.0). Cumulative probability of FTD and difference of its risk by preregion was calculated by the Kaplan-Meier procedure and $\log$ rank test, respectively. For comparison of symptoms and treatment-seeking behaviors for TD, $\chi^{2}$-test was conducted using the Epi Info 6 programme.

The data were also analyzed by region visited prior to arrival in Thailand; i.e., a) directly from Japan, b) via other countries in Southeast Asia, and c) via other countries outside Southeast Asia.

\section{RESULTS}

\section{Characteristics of Japanese travelers}

The characteristics of the 327 Japanese travelers are shown in Table 1 . Men accounted for $66 \%$ of the subjects. Mean and median age was 27 and 25 years old, respectively, with $85 \%$ of subjects being less than 30 years old. Most travelers were single $(91 \%)$, and high school graduates
Table 1 Characteristics of 327 Japanese travelers to Bangkok, Thailand

\begin{tabular}{|c|c|}
\hline Characteristic & $N(\%)$ \\
\hline Sex, male & $215(65.7)$ \\
\hline Age* (year) $^{*}$ & $26.8(25 / 19-66)$ \\
\hline Marital status, single & $298(91.1)$ \\
\hline \multicolumn{2}{|l|}{ Educational level } \\
\hline$\geq$ High school & $318(97.3)$ \\
\hline \multicolumn{2}{|l|}{ Occupation } \\
\hline Unemployed/Retired & $124(37.9)$ \\
\hline Student & $104(31.8)$ \\
\hline Worker & $84(25.6)$ \\
\hline Housewife & $6(1.8)$ \\
\hline Others & $9(2.8)$ \\
\hline Travel with companions & $154(47.1)$ \\
\hline First visit to Thailand & $116(35.5)$ \\
\hline Purpose of travel, sightseeing & $300(91.7)$ \\
\hline Travel style, self-arranged journey & $310(94.8)$ \\
\hline \multicolumn{2}{|l|}{ Pre-regions prior to Thailand } \\
\hline Japan & $136(41.6)$ \\
\hline Southeast Asia & $117(35.8)$ \\
\hline Other regions & $74(22.6)$ \\
\hline Duration of stay* (day) & $6.2(4 / 1-21)$ \\
\hline Total expenditure per day† (US\$) & $17.9(9.1 / 2.3-204.5)$ \\
\hline
\end{tabular}

* Mean (median/range). $†$ Mean (median/range), thirteen missing.

(97\%). Unemployed /retired persons accounted for 38\%, followed by students (32\%) and workers $(24 \%)$. Fifty-three percent of travelers traveled alone, and $35 \%$ were first visitors to Thailand. Most travelers visited Thailand for sightseeing (92\%), and arranged their trip by themselves (95\%). Forty-two percent arrived directly from Japan while 36\% came to Thailand via other countries in Southeast Asia like Vietnam, Cambodia, and Laos. Others came from Nepal, India, Australia, the U.S.A. and so on. Mean and median days of stay in Thailand up to the day of interview were 6.2 and 4.0, respectively. Their mean daily expenditure was 17.9 US dollars with median of 9.1 US dollars.

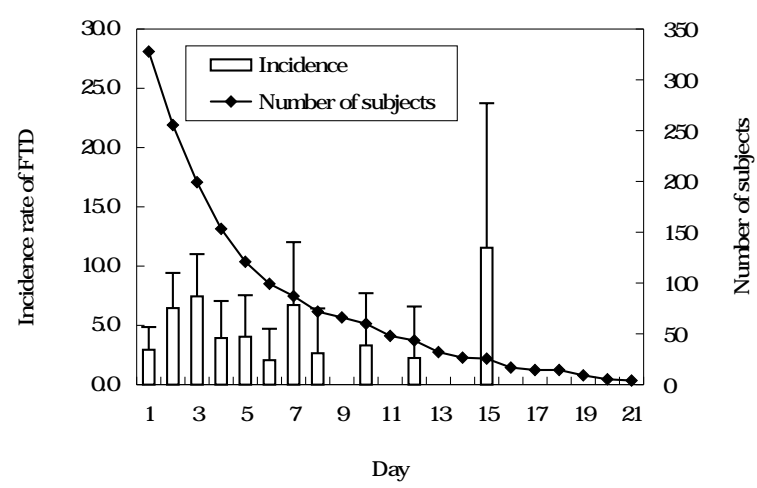

*Bars present $95 \%$ confidence interval for each incidence of FTD

Figure 1 Daily incidence of first episode of travelers' diarrhea (FTD) and number of subjects at risk 
Number of subjects at FTD risk and incidence of FTD

The number of subjects at risk for FTD was 327 on the first day of stay and decreased to 88 on the seventh day and 28 on the 14th day (Figure 1). Sixty-nine travelers developed diarrhea. Of them, 33\% (23 travelers), 49\%, (34 travelers) and $17 \%$ (12 travelers) had classic TD, moderate TD and mild TD, respectively. Most FTD (91\%, 63 travelers) clustered within the first 8 days after arrival to Thailand. The incidence rates during these eight days ranged between $2.7 \%$ and $7.5 \%$ with the highest incidence on the third day. Occurrences of FTD were sporadic between Days 9 and 15 . No FTD was reported after Day 16.

\section{Cumulative probability of FTD}

Survival probability without experiencing FTD up to Day $\mathrm{N}$ was calculated by the Kaplan-Meier survival analysis. Then, the cumulative probability of FTD to Day N (\%) was calculated by subtracting the above from 1.0. Figure 2 shows the cumulative probabilities of FTD by pre-region (a. directly from Japan, b. via other countries in Southeast Asia, and c. via other countries outside Southeast Asia). The cumulative probability of FTD at Day 7 by pre-regions was $19 \%$ for those arriving directly from Japan, $42 \%$ for those arriving directly from Southeast Asian countries, and 25\% for those arriving from other regions. The cumulative probability of FTD in travelers via Southeast Asia was more than twice as that in those from Japan. The cumulative probability of FTD for those arriving from Japan, Southeast Asian countries and other regions reached $26 \%, 47 \%$, and $32 \%$, respectively, by Day 14 . According to a log-rank statistic test, travelers who arrived in Thailand via other Southeast Asian countries developed FTD significantly more frequently than those arriving directly from Japan $(P<0.005)$ and showed a marginally higher incidence of TD than those arriving via other regions $(P<0.1)$.

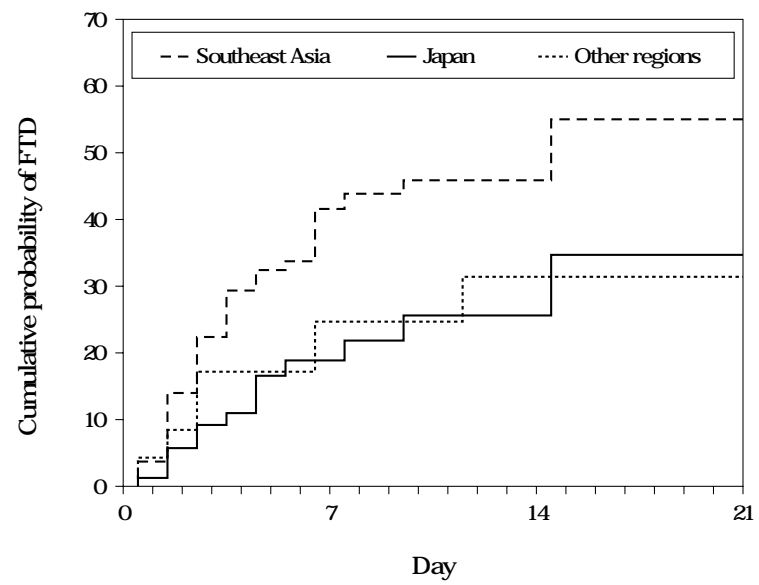

Figure 2 Cumulative probability of FTD by pre-region among Japanese travelers in Bangkok, Thailand

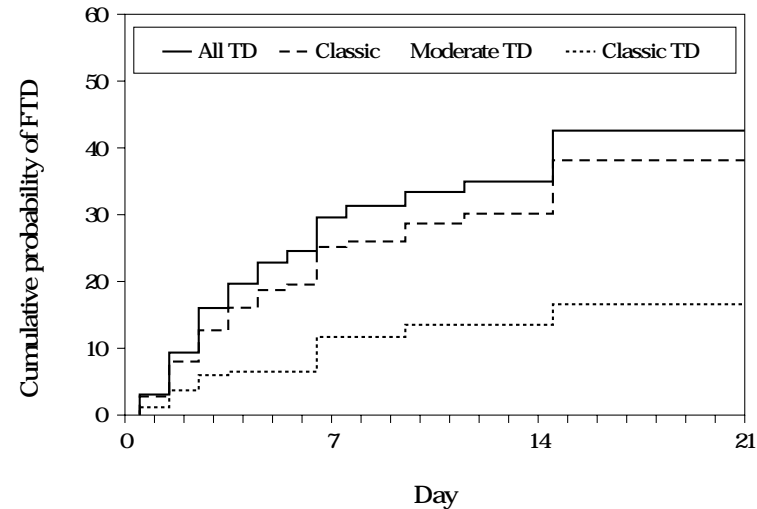

Figure 3 Cumulative probability of FTD due to classification of FTD among Japanese travelers in Bangkok, Thailand

Figure 3 shows the cumulative probability of classic $\mathrm{TD}$, moderate TD, and mild TD. Cumulative probability of FTD at Day 7 was $12 \%$ for classic TD, $25 \%$ for classic plus moderate TD, and $29 \%$ for all forms of TD including mild cases. Cumulative probabilities reached to $13 \%, 30 \%$, and 35\%, respectively, by Day 14 .

Cumulative probability of classic plus moderate TD at Day 7 was the highest among travelers from Nepal (56\%), followed by travelers from Laos (42\%), Vietnam (39\%), and Cambodia (38\%), while it was only $12 \%$ among travelers who arrived directly from Japan.

Symptoms and treatment-seeking behaviors among 69 travelers with $T D$

The mean daily number of stools and its standard deviation was $4.4 \pm 1.9$ for classic TD, $2.8 \pm 2.2$ for moderate

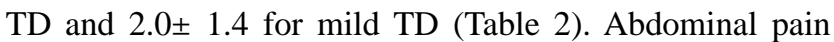
was reported in $91 \%$ of classic TD, a rate significantly

Table 2 Symptoms and reactions among 69 travelers with TD

\begin{tabular}{lccc}
\hline Variable & $\begin{array}{c}\text { Classic } \\
(n=23)\end{array}$ & $\begin{array}{c}\text { Moderate } \\
(n=34)\end{array}$ & $\begin{array}{c}\text { Mild } \\
(n=12)\end{array}$ \\
\hline Sex: no. male/no. female & $17 / 6$ & $19 / 15$ & $9 / 3$ \\
Mean frequency of unformed & & & \\
$\quad$ stools $( \pm$ SD) of diarrhea & $4.4 \pm 1.9$ & $2.8 \pm 2.2$ & $2.0 \pm 1.4$ \\
Symptoms: \% of patients & & & \\
Fever & 13.0 & 8.8 & \\
Nausea/Vomiting & 26.1 & 14.7 & \\
Abdominal pain & $91.3 *$ & 44.1 & \\
Bloody stool & 13.0 & 2.9 & \\
$\quad$ Watery stool & 56.5 & 20.6 & 50.0 \\
Reactions for TD: \% of patients & & & \\
Taking medicine carried from homeland & 47.8 & 38.2 & 41.7 \\
$\quad$ Buying medicine in Thailand & $34.8 *$ & 8.8 & 8.3 \\
Taking ORS (oral rehydration salt) & 21.7 & 8.8 & \\
Visiting clinic & 13.0 & 8.8 & \\
Taking only rest without any treatment & 21.7 & 47.1 & 50.0 \\
\hline * $<$ 0.05 compared with Moderate TD. & & &
\end{tabular}


higher than in cases of moderate TD $(44 \%, P<0.05)$. Watery diarrhea was documented in $57 \%$ of classic TD, $21 \%$ of moderate TD and in $50 \%$ of mild TD. Nausea or vomiting was documented in $26 \%$ of classic TD and $15 \%$ of moderate TD. Fever was reported in $13 \%$ of patients with classic TD and in $9 \%$ of those with moderate TD. Bloody diarrhea was documented in $13 \%$ of patients with classic TD but in only $3 \%$ of those with moderate TD.

Table 2 also shows the treatment-seeking behaviors of patients with TD. Regardless of severity, $38 \%$ to $48 \%$ of patients took medicine that they brought from Japan. Patients with classic TD bought medicines in Thailand significantly more frequently than those with moderate TD $(P<0.05)$. the proportion of those having taken ORS was also higher in classic TD than in moderate TD. The proportion of those taking only rest without any treatment tended to be less in classic TD $(22 \%)$ than in moderate $(47 \%)$ or mild TD (50\%). Six travelers who suffered from TD visited clinics. Of them, 2 travelers visited clinics without taking any medicine from Japan. Two travelers visited a clinic after taking medicines brought from Japan, and the remaining two travelers bought medicines in Thailand before they went to the clinics.

\section{DISCUSSION}

TD generally resolves within a few days, but $10-20 \%$ of cases last for more than 7 days (Cobelens et al., 1998; Mattila, 1994). In the case of long-lasting or continual diarrhea, it is difficult for travelers to distinguish the first episode of TD from subsequent episodes. This study therefore focuses on the first episode of TD after entry to Thailand. Because Japanese travelers stay an average of 5.6 days in Thailand (Immigration Bureau, Police Department in Thailand, 2001), the first episode of TD is more important for Japanese travelers than subsequent episodes.

This study was conducted in the Khaosan Road area, Bangkok, Thailand. This area is a popular venue for young backpackers. Currently, many backpackers visit there from all over the world, because of its friendly atmosphere and low-cost accommodation and food. Discount air tickets and useful trip information are available in the Khaosan Road area. Backpackers are generally considered to prefer an adventurous travel style and to be more exposed to risk of diarrhea (Steffen, 1986). Self-arranged travel is also at higher risk for diarrhea than organized travel (Cobelens et al., 1998). Increasing age is negatively correlated with diarrhea (Steffen, 1986; Cobelens et al., 1998). Steffen et al. (1999) found that teenagers and young adults were at a higher risk for TD, probably due to their great appetite and consequent ingestion of a higher dose of pathogens. Since the age of the subjects in the present study clustered undter the age of 30 years, this age group is probably to be at a higher risk of acquiring TD than other older age groups.

FTD clustered within the first 8 days of arrival in Thailand in the present study (Figure 1). As in previous reports (Angust and Steffen, 1997; Steffen, 1986), TD started within the first day after entry to Thailand, and showed the highest proportion of onsets on the third day. About one in three travelers to Thailand $(30 \%)$ had TD within the first week, $35 \%$ of travelers developed TD within 14 days, and $43 \%$ within 21 days (Figure 3 ). This increased proportion of cumulative probability of TD also shows the highest risk of FTD within the first week of stay.

Risk of TD was found to vary by season (Mattila et al., 1992). Since the present study was conducted in the cooler season (January to February) in Thailand, the incidence and cumulative probability of FTD are expected to be higher in the warmer season.

Among the 136 travelers arriving in Thailand directly from Japan, 18 (13.2\%) experienced TD. The cumulative probability of FTD was $19 \%$ within the first week, $26 \%$ within the two weeks, and $35 \%$ within three weeks (Figure 2 ). This shows that TD occurred more frequently during the first week even among those who came directly from Japan. The cumulative probability on Day 14 was similar to the incidence reported by Steffen (1986). The cumulative probability on Day 20 was also similar to the incidence of TD among American troops stationed in Thailand (Beecham et al., 1997). Japanese travelers in Thailand seem to experience TD at a rate similar to that of European travelers (Steffen, 1986). Although most subjects in the present study were young backpackers, this does not seem likely to exert a significant influence on TD occurrence.

Regional variations prior to entry in to Thailand influenced TD occurrence (Figure 2). According to log-rank test, travelers who arrived Thailand via other Southeast Asian countries developed TD at a significantly higher rate than those arriving directly from Japan $(P<0.005)$. It is suspected that travelers arriving via Southeast Asia were exposed to more TD agents before Thailand than those arriving directly from Japan. The difference in cumulative probability of FTD between travelers arriving via Southeast Asia and from Japan may be due to the dose and type of causative agents ingested in previous regions. The difference was 23 points at Day 7, and 21 points at Day 14. The effect of pre-region on occurrence of TD was stronger during the first week. The evidence of the effect of pre-region indicates that travelers might import pathogens from surrounding countries to Thailand. This may also affect the health of the Thai people.

Pre-regions other than Southeast Asia included high- 
risk destinations such as India and Nepal (Hill, 2000; von Sonnenburg et al., 2000). The cumulative probability of FTD via these areas was thought to be high before the analysis. But in reality, it was similar to that from Japan. this may be due to a seasonal variation (Mattila et al., 1992) and to the inclusion of developed countries such as the U.S. A. and Australia in "other pre-region". Since the January to February Period is winter in India and Nepal and the incidence of diarrhea is low (Hoge et al., 1996), the effect of pre-regions might not reflect strongly on the cumulative probability of FTD in the present study.

Cobelens et al. (1998), Hill (2000) and Mattila (1994) reported that $34-80 \%$ of patients with TD had abdominal pain, $17-42 \%$ had fever, $18-45 \%$ had nausea or vomiting, 28 $-69 \%$ had watery stool, and $0-5 \%$ had bloody stools. The present study showed a similar occurrence of these symptoms. Although TD is a self-limiting illness and generally resolves within a few days, the severity of TD influences the activity of travelers: $48 \%$ of patients suffering from classic TD took medicine, and $13 \%$ visited clinics. These actions of Japanese travelers are similar to the finding of Hill (2000) and Steffen et al. (1999). However, more Japanese travelers with mild TD took medicine than the travelers studied by Steffen et al. (1999; 43\% vs. 5\%). Japanese travelers tended to take medicine more easily, but $47-50 \%$ of travelers with moderate and mild TD took only rest without any medication. Japanese travelers are likely to consider diarrhea as slight or not severe.

A high proportion of Japanese travelers took medicine brought from Japan. However, antibiotic resistances has been found, recently among diarrheal pathogens (Hoge et al., 1998; Matushita et al., 2000) and some antibiotics are not effective for diarrhea. It is important for travelers to know the efficacy of the medicines they carry, and to be familiar with procedures needed to obtain safe and effective medical care.

Finally, three million Japanese travel to South Asia annually, and many of them are at high risk of acquiring TD. Nevertheless, the epidemiological study of Japanese TD has never been conducted in South Asia before. The present study provides basic epidemiological data concerning the incidence of Japanese TD and the reactions to TD. However, many factors such as various pathogens, travel destination, length of stay, food consumption and so on (Ueda et al., 1996; Cobelens et al., 1998; Ryan and Kain, 2000)are related to the occurrence of TD. Therefore, further investigations are needed to provide appropriate and valuable advice to Japanese travelers on how to avoid and treat TD.

\section{ACKNOWLEDGEMENT}

This study was approved by the Ethical Review Research Committee of Mahidol University, Bangkok, Thailand.

We thank the Japanese travelers in Thailand who participated in this study. Thanks are also extended to Dr. Nawarat Suwannapong, Department of Public Health Administration, Faculty of Public Health, Mahidol University for her kind and helpful advice.

\section{REFERENCES}

Angst, F. and Steffen, R. (1997): Update on the epidemiology of traveler's diarrhea in East Africa. J. Travel. Med., 4, 118120.

Beecham, H. J. 3rd., Lebron, C.I. and Echeverria, P. (1997): Short report: impact of traveler's diarrhea on United States troops deployed to Thailand. Am. J. Trop. Med. Hyg., 57, 699701.

Black, R. E. (1990): Epidemiology of traveler's diarrhea and relative importance of various pathogens. Rev. Infect. Dis., 12 (suppl 1), S73-79.

Cobelens, F. G. J., Leentvaar-Kuijpers, A., Kleijnen, J. and Coutinho, R. A. (1998): Incidence and risk factors of diarrhoea in Dutch travelers: consequences for priorities in pretravel health advice. Trop. Med. Int. Health., 3, 896-903.

Echeverria, P., Blackow, N. R., Stanford, L.B. and Cukor, G.G. (1981): Travelers' diarrhea among American Peace Corps volunteers in rural Thailand. J. Infect. Dis., 143, 767-771.

Hill, D. R. (2000): Occurrence and self-treatment of diarrhea in a large cohort of Americans traveling to developing countries. Am. J. Trop. Med. Hyg., 62, 585-9.

Hoge, C. W., Shlim, D. R., Echeverria, P., Rajah, R., Herrmann, J. E. and Cross, J. H. (1996): Epidemiology of diarrhea among expatriate residents living in a highly endemic environment. JAMA, 275, 533-8.

Hoge, C. W., Gambel, J. M., Srijan, A., Pitarangsi, C. and Echeverria, P. (1998): Trends in antibiotics resistance among diarrheal pathogens isolated in Thailand over 15 years. Cli. Infec. Dis., 26, 341-345.

Matsushita, S., Kawamura, M., Takahashi, M., Yokoyama, K., Konishi, N., Hatakeyama, K., Kai, A., Morozumi, S., Morita, K., Watanabe, N., Kanamori, M. and Kudoh, Y. (2001): Increasing fluoroquinolone low-sensitivity in enterotoxigenic Escherichia coli isolated from diarrhea of overseas travelers in Tokyo. Kansenshougaku Zasshi, 75, 785-791.

Mattila, L., Siitonen, A., Kyronseppa, H., Simula, I., Oksane, P., Stevik, M., Salo, P. and Peltola, H. (1992): Seasonal variation in etiology of travelers' diarrhea. J. Infect. Dis., 78, 51922.

Mattila, L. (1994): Clinical features and duration of traveler's diarrhea in relation to its etiology. Clin. Infect. Dis., 19, 72834.

Ryan, E. T. and Kain, K.C. (2000): Health advice and immu- 
nizations for travelers. N. Eng. J. Med., 342, 1716-1725.

Steffen, R. (1986): Epidemiologic studies of travelers' diarrhea, severe gastrointestinal infectional infections, and cholera. Rev. Infect. Dis., 8 (suppl 2): S122-30.

Steffen, R., Collard, F., Tornieporth, N., Campbell-Forrester, S., Ashley, D., Thompson, S., Mathewson, J.J., Maes, E., Stephenson, B., DuPont, H.L. and von Sonnenburg, F. (1999): Epidemiology, etiology, and impact of traveler's diarrhea in Jamaica. JAMA, 281, 811-7.

Taylor, D. N., Echeverria, P., Blaser, M. J., Pitarangsi, C., Blacklow, N., Cross, J. and Weniger, B.G. (1985): Polymicrobial aetiology of travelers' diarrhoea. Lancet, 1, 381-3

Ueda, Y., Suzuki, N., Mori, H., Miyagi, K., Noda, K., Hirose,
H., Takegaki, Y., Hashimoto, S., Oosumi, Y., Miyata, Y. and Taguchi, M. (1996): Bacteriological studies of travellar's diarrhoea. 5) Analysis of enteropathogenic bacteria at Osaka airport quarantine station from January 1992 through September 3rd, 1994. Kansenshougaku Zasshi, 70, 29-41.

von Sonnenburg, F., Tornieporth, N., Waiyaki, P., Lowe, B., Perusuki, L. F.Jr., DuPont, H. L., Mathewson, J.J. and Steffen, R. (2000): Risk and aetiology of diarrhea at various tourist destinations. Lancet, 356, 133-134.

Wittlinger, F., Steffen, R., Watanabe, H. and Handszuh, H. (1995): Risk of Cholera among western and Japanese travelers. J. Travel. Med., 2, 154-158. 